\title{
Stress-strain connection analysis of bolted joints for thin-walled steel profiles working in tension and compression
}

\author{
Evgeniy Ustimenko ${ }^{1, *}$, Sergey Skachkov ${ }^{1}$, Elena Vinogradova ${ }^{1}$, and Genrikh Muro ${ }^{1}$ \\ ${ }^{1}$ Don State Technical University, 344002, Rostov-on-Don, Russia
}

\begin{abstract}
The issues of designing structures from thin-walled profiles with nodal joints on bolts are considered, a method of strength calculation is developed. The calculation takes into account two variants of bolted joints on high-strength bolts and unregulated tightening connections, two variants of the operation of a shear-resistant connection with a "breakdown" when overcoming the force over the friction force of the contact surfaces and without a "breakdown". The methodology includes the bolted connection splitting for the elements working in tension and compression.
\end{abstract}

\section{Introduction}

The article presents a methodology developed by the authors for calculating multi-bolt shear-resistant joints of thin-walled steel profiles. The calculation technique is based on the results of experimental-theoretical studies of multi-bolt compounds performed by the authors and the study of other researchers.

\section{Targets and goals}

The main objectives of the study are:

1. The study of shear-resistant bolted joints' work;

2. Method development for calculating bolted joints of thin-walled profiles.

\section{Literature review}

Regulatory methods for calculating multi-bolt connections is based on the multiplication result obtained using the universal formula multiplied by the number of bolts in the connection [1.7], which means a proportional distribution of stresses from the first bolt to each subsequent one. This method does not reflect the actual operation of multi-bolt joints, since the results of field tests by many researchers show $[2,3]$ that stresses in the edges of the holes from the first to subsequent bolts in a row are not distributed proportionally, in the direction of reduction. In a multi-bolt connection of thin-walled elements working in

* Corresponding author: ustim2009@yandex.ru 
tension in the edge of the opening of the first bolt, breaking forces occur in places perpendicular to the axial force. In the zone of influence on the edges of a thin-walled plate of bolts, the stress is much less than in places of their concentration. Field tests confirm that fracture of a multi-bolt joint in tensile elements occurs as a result of rupture of the hole edges for the first bolt due to stress concentration [2,3]. This shows the incorrectness of the method for calculating multi-bolt connections with domestic and foreign standards.

Results analysis of multi-bolt joints' studies using the ultimate element method showed that the operation of multi-bolt joints in elements working in tension and compression has fundamental differences [6]. The stress concentration of the multi-bolt joints for the elements working in compression also occurs in the region of the first bolt, but along the direction line of the axial force. In this case, stress concentrations arise at the place of the bolt impact on the hole edge and decrease in the second and subsequent bolts, which does not correspond to the used design scheme in norms [1, 7].

It was shown in [3] that stress development of a friction joint can proceed according to two and four-stage operation schemes. The four-stage work scheme proceeds when the value of the bearing capacity for flow exceeds the carrying capacity according to the shear criterion. The two-stage operation connection scheme occurs when the value of the connection bearing capacity exceeds the shear criterion over the bearing capacity according to the yield criterion [4]. The two-stage operation scheme often proceeds when using highstrength bolts, since the connection work is due to friction forces [3]. The scheme according to which the operation of the bolted joint will proceed depends on many other factors [4], such as the time at which the joint was without load, cleaning the edges of the holes from burrs, degreasing of the surface, etc. Friction bolted joints of thin-walled profiles have a significantly larger bearing ability than bolted connections with unregulated tightening [2].

The basic method for calculating bolted joints in [1,7] is based on the resistance to crushing of the base metal and is determined by the formula:

$$
\begin{gathered}
F_{b}=\alpha \cdot \frac{R_{u n}}{\gamma_{m}} \cdot d \cdot t, \\
F_{b, R d}=2.5 \cdot \alpha_{b} \cdot \frac{K_{t} \cdot f_{u}}{\gamma_{m 2}} \cdot d \cdot t,
\end{gathered}
$$

These formulas more accurately reflect the operation of a single bolt compound. With the addition of the 2-nd, 3-rd and 4-th bolt along the force of the first bolt edge, additional stress will arise due to the elongation of the thin-walled profile relative to each subsequent bolt. Thus, in the edge of each subsequent bolt, the voltage will decrease, and in the first increase.

\section{Multi-bolt friction joints' calculation method}

The formula of crushing edges' resistance must be divided into two types. The first type is when calculating compressed rods, the second type is when calculating stretched rods. With a single bolt connection, both types will be the same.

It is proposed to introduce several components into the basic formula of regulatory documents $[1,7]$ to determine the bearing capacity of stretched rods:

1) In order to calculate the edges' crushing, it is necessary to determine the force at

which a shift (stall) occurs of the contact surfaces:

$F_{\text {shift }}=\mu \cdot n_{b} \cdot N_{\text {shaft }}$, where $\mu$ is the coefficient of friction, $n_{b}$ is the number of bolts in a row, $N_{\text {shaft }}$ is the force in the bolt shaft. This formula will help to determine the voltage at the edges of the bolt holes more accurately.

If $F_{\text {edge }}<F_{\text {shift }}$, then the edges' fracture occurs before the shift. Where in

$F \leq F_{\text {edge }}$, the force in the shaft should be less than the force at which the edges break. 
where $\mathrm{F}$ is the calculated force in the shaft, $F_{\text {edge }}$ is the force at which a fracture of the hole edges for the first bolt occurs,

2) With an increase in the number of bolts more than one in a row, it is necessary to take into account the redistribution of forces along the edges:

$$
F_{b}=\sum_{k=1}^{n}\left[\alpha \cdot \frac{R_{u n} \cdot \gamma_{\mathrm{p}}}{\gamma_{m}} \cdot d \cdot t\right]
$$

where $\gamma_{p}$ is the stress redistribution coefficient under tensile force from the second to the last bolt in a row, this coefficient must be derived by full-scale testing of multi-bolt joints.

3) The force $F_{b}$, perceived by the multi-bolt connection of one row, should not exceed the force $F_{\text {edge }}$, at which a fracture of the hole edges for the first bolt occurs. To determine the dependence of the edges fracture on the thickness of the metal, it is necessary to conduct a series of field tests.

As a result, we obtain an expression for determining the strength of shear-resistant bolted joints of one row:

$$
F_{b}=\sum_{k=1}^{n}\left[\alpha \cdot \frac{R_{u n} \cdot \gamma_{\mathrm{p}}}{\gamma_{m}} \cdot d \cdot t+\mu \cdot N_{\text {shaft }}\right]
$$

$F_{b} \leq F_{\text {edge }}$; this inequality is valid only for the calculation of tensile rods, during compression work since the edges' fracture is excluded.

The calculation of multi-bolt joints for structural elements working in compression must be carried out according to the same principle. The basic formula must include the force of friction and the redistribution of stresses on the hole edges.

$$
F_{b}=\sum_{k=1}^{n}\left[\alpha \cdot \frac{R_{u n} \cdot \gamma_{c o m p}}{\gamma_{m}} \cdot d \cdot t+\mu \cdot N_{\text {shaft }}\right] ;
$$

where $\gamma_{\text {comp }}$ is a coefficient taking into account the redistribution of stresses with compressive force from the second to the last bolt in a row.

\section{Summary}

1. As a theoretical studies' result, shortcomings in existing methods for calculating bolted joints of thin-walled profiles were identified.

2. A calculation method is proposed that allows refining the calculation of shear-resistant bolted joints for shifts operating in tension and compression.

Recommendations and prospects for further development of the topic are carrying out theoretical and experimental studies of multi-bolt joints to determine the coefficient of stress redistribution in the region of the second and subsequent bolts.

\section{References}

1. SP 260.1325800.2016 Thin-walled steel structures made of cold-formed galvanized profiles and corrugated sheets: Approved by order of the Construction Ministry of the Russian Federation, December 3, 2016 No. 881, p.116.

2. A.V. Tarasov, PhD Thesis Krasnoyarsk, 2013.

3. A.V. Korotkikh, I.I. Krylov, V.G. Cherkasov, University News. Construction, 2, 3-14 (2011). 
4. A.S. Chesnokov, A.F. Knyazhev, Shear-resistant joints on high-strength bolts (Stroyizdat, Moscow, 1974).

5. E.E. Ustimenko, S.V. Skachkov, Science and World Publishing House: Scientific Review, 2 (42), 1, 4 (2017). ISSN: 2308-4804-2017.

6. E.E. Ustimenko, S.V. Skachkov, Materials Science Forum, 974, 672-675 (2019). ISSN: $1662-9752-2019$

7. Eurocode 3. Design of Steel Structures. Part 1.3. Supplementary rules for cold-formed members and sheeting. CEN. 2004, 125 p.

8. S.A. Isaev, P.A. Baranov, N.I. Vatin, Y.V. Zhukova, A.G. Sudakov. Technical Physics Letters. 2014. 40(8). Pp. 653-656. DOI:10.1134/S1063785014080057.

9. Z. Jakšic, D. Ladjinović, M. Trivunić, N. Harmati, N. Vatin. Procedia Engineering. 2015. 117(1). Pp. 502-515. DOI:10.1016/j.proeng.2015.08.252.

10. S. Klyuev, A. Klyuev, N. Vatin. MATEC Web of Conferences. 2018. 245. DOI:10.1051/matecconf/201824503006.

11. B. Kovačič, R. Kamnik, A. Pustovgar, N. Vatin. Procedia Engineering. 2016. 165. Pp. 918-925. DOI:10.1016/j.proeng.2016.11.801. 